\title{
New evidence of contaminants from fracking
}

\author{
- Cite as: CMAJ 2017 August 8;189:E1025-6. doi: 10.1503/cmaj.1095459
}

Posted on cmajnews.com on July 20, 2017.

$\mathbf{N}$ ew evidence has emerged indicating that wastewater from fracking contains compounds harmful to human health. Fracking, a controversial technique for extracting oil and gas, involves injecting a water mixture deep into the ground to force open existing fissures. The process produces wastewater containing a number of contaminants.

New evidence published July 12 in Environmental Science and Technology suggests that wastewater treatment plants do not effectively remove a number of these contaminants - some of which are known carcinogens and endocrine-disrupting compounds. These pollutants are discharged to surface water and may end up in the drinking water of downstream communities.

The research team, led by Dr. William Burgos, who is a professor of environmental engineering at Pennsylvania State University, studied contaminants in sediment layers in the Conemaugh River Lake in western Pennsylvania. This lake receives treated wastewater from fracking at the Marcellus Shale. Burgos' team took core samples from the lake bottom to obtain an historical assessment of contaminants that had accumulated. Peak levels of contaminants were found in the sediment layer dated between 2008 and 2012, coinciding with the time period when the oil and gas industry moved from conventional drilling to fracking of the Marcellus Shale.
Their analysis detected elevated levels of organic compounds, radionuclides, salts and metals. The top two organic compounds were surfactants and polyaromatic hydrocarbons. The surfac- was five picocuries per gram... which is at the threshold for having to segregate it and consider it a potentially radioactive waste."

But according to Burgos, elevated bromide levels measured in the sediment

\section{Study adds to growing body of evidence that fracking may adversely affect human health}

tants, nonylphenol ethoxylates, are suspected of being endocrine disrupting, the polyaromatic hydrocarbons are known carcinogens. may be the biggest reason for concern. "If we as a society start to add bromide to our surface water, we run the risk of exposing ourselves to elevated concen-

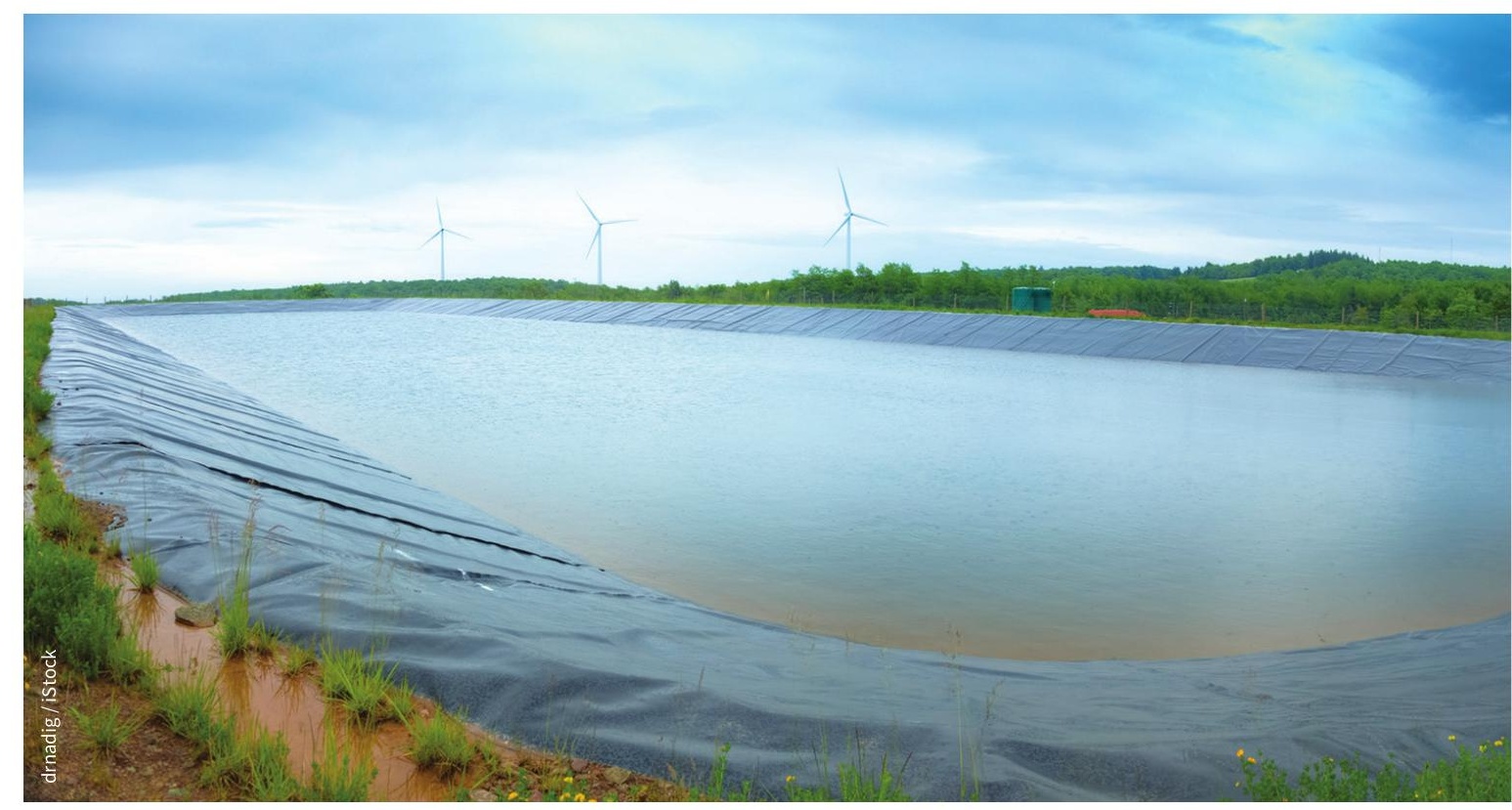

Carcinogens from fracking found in waterways.
Radium, a radionuclide found in the sediment, is also a known human carcinogen. Burgos told CMAJ, "the highest concentration [of radium measured in solids] trations of [carcinogenic] brominated disinfection by-products," he said. "We think that the bromide levels in the surface waters are - as far as in the human 
health impact realm - the potentially most direct."

Should people living in communities downstream from wastewater treatment plants be concerned? Burgos says if he lived in Pittsburgh, he would monitor quarterly reports from the water authority. "Maybe I would use something like a carbon filter on the water before I drank [the water], in the hopes that these disinfection by-products, because they are organic compounds, might adsorb to the carbon and I could remove them." Communities closer to the wastewater treatment plants may have more reason to worry, he added.

This study adds to the growing body of evidence suggesting that fracking may adversely affect human health. A Yale Pub- lic Health Analysis in January 2017 reviewed the chemicals released into the air and water as a result of fracking - 55 chemicals were identified that may cause cancer, including 20 that have been shown to increase the risk of leukemia and lymphoma.

Previously, the Canadian Association of Petroleum Producers (CAPP) told CMAJ that the shale gas industry is taking steps to alleviate public health concerns. CAPP has funded an air monitoring system in BC, and has lobbied government to mandate the disclosure of chemicals used. In 2012, both BC and Alberta made disclosure mandatory.

In Pennsylvania, tighter regulations on fracking wastewater came into effect in 2011. Burgos and colleagues noted a reduction in the levels of harmful contaminants in the sediment layers dated after those regulations came into effect. Agencies could do more to ensure that these regulations are enforced, notes Burgos.

The question of synergistic effects of co-occurring fracking pollutants on health outcomes has yet to be explored. "The [full] impact of that layer of sediment with elevated concentrations of all of these pollutants to ecosystem services that the lake provides or to human health is essentially unknown at this point," says Burgos. "It's an open question."

Emily Hughes, CMAJ 